\title{
Pentalogy of Fallot in a Crioulo Foal
}

\section{Ana Carolina Barreto Coelho ${ }^{1}$, Lorena Alvariza Amaral ${ }^{2}$, Carlos Anselmo dos Santos ${ }^{2}$, Jairo Jaramillo Cardenas ${ }^{3}$, Clairton Marcolongo-Pereira', Adriana Lücke Stigger' \& Ana Lucia Schild'}

\begin{abstract}
Background: Cardiac anomalies account for 3.5\% of congenital defects in horses. Tetralogy of Fallot (TOF) is characterized by ventricular septal defect, pulmonary stenosis, dextroposition the aorta and right ventricular hypertrophy secondary. Pentalogy of Fallot (POF) is a variation and is characterized by a defect in the right atrioventricular valve or persistence of the ductus arteriosus, in addition to the other defects observed in tetralogy. Affected animals usually have stunted growth, exercise intolerance, weakness, lethargy, cyanosis, dyspnea and syncope. The aim of this study was to describe a case of POF, as diagnosed in a Crioulo foal in southern Brazil.

Case: Clinical signs were observed at the fifth day of life and were characterized by cyanosis, intense tracheal stertor, tachycardia, marked heart murmur, HR $160 \mathrm{bpm}$, RR 80 breaths/min, T $39.8^{\circ} \mathrm{C}$ and syncope. These signs worsened with physical activity. Endoscopic evaluation of the upper airways revealed no anatomical conformation changes or tissue dysfunction. A cardiac ultrasound showed a loss of continuity of the interventricular septum, right ventricular wall thickening and a hyperechoic appearance of the area where the right atrioventricular valve (tricuspid) should be. The crises have become more severe and more frequent, the animal began to show signs of ischemia, such as loss of motor coordination and limited mobility. The foal died at 15 days old. At necropsy the liver was congested and had a nutmeg appearance, there was foam in the trachea, and the lungs were edematous. There was hydropericardium, and the heart was increased in size with a globoid shape. The heart had thickening of the walls of the right and left ventricle and pulmonary artery stenosis. There was also an oval orifice $2.5 \mathrm{~cm}$ in diameter in the interventricular septum connecting the ventricles (ventricular septal defect), an overriding aorta and aplasia of the tricuspid valve. Histologically the liver had centrilobular to mediozonal necrosis, and there was pulmonary edema and congestion.

Discussion: The diagnosis of pentalogy of Fallot was based on the clinical signs, the ultrasound results and the macroscopic lesions observed at necropsy. Tetralogy of Fallot is one of the most common congenital cardiac malformations observed in horses, however, in a study of congenital malformations in this species, only 3.5\% had cardiac malformations out of the 608 foals examined. The prevalence of heart defects in horses compared with other domestic species is relatively low $(0.1 \%-0.5 \%)$. In this case, the malformation was probably sporadic because the foal was the only animal to be born with this malformation on the farm. In the Crioulo breed, congenital defect reports are scarce. In a retrospective study of equine diseases in southern Brazil over a period of 35 years, malformations were not observed in 708 horses of this breed, which is the predominant breed in the region. In the present case, the fact that the mare had another three healthy foals with the same stallion reduces the possibility that this was a case of hereditary origin. It is likely that this case is of a sporadic nature with no chance of determining the cause. The differential diagnoses in animals with lethargy, cyanosis, and exercise intolerance or syncope include complicated or multiple cardiac defects. There are no previous reports of TOF and POF in the Crioulo breed in Brazil.
\end{abstract}

Keywords: Pentalogia de Fallot, cardiac ultrasound, cardiac malformation, horse. 


\section{INTRODUCTION}

Cardiac anomalies account for $3.5 \%$ of congenital defects in horses. The most commonly reported congenital cardiac defects are ventricular septal defects, aortic stenosis, and tetralogy of Fallot [10]. Tetralogy of Fallot (TOF) is one of the most common congenital heart defects in horses, and is characterized by pulmonary valve stenosis, right ventricular hypertrophy, overriding aorta, and ventricular septal defect [2]. This defect has been described in dogs, cats, horses, cattle, sheep, monkeys, bears, panthers [9] and humans [1]. Pentalogy of Fallot is a variation of TOF and is characterized by a defect in the right atrioventricular valve or persistence of the ductus arteriosus, in addition to the other defects observed in tetralogy.

The aim of this study was to describe a case of pentalogy of Fallot diagnosed in a Crioulo foal in southern Brazil.

\section{CASE}

A seven-day-old male Criolo horse was treated in a breeding facility in Pelotas / RS with a history of syncope. Clinical examination showed HR: 160 bpm; RR: 80 breaths $/ \mathrm{min}$; cyanosis; $\mathrm{T} 39.8^{\circ} \mathrm{C}$; intense tracheal stridor and marked heart murmur. Emergency treatment was carried out with corticosteroids $\left(\text { Cortvet }^{\circledR}\right)^{1}$, ceftiofur $\left(\text { Excenel }^{\circledR}\right)^{2}$, and blood plasma from the mare, showing no clinical improvement. The syncope frames were related to increased physical activity, with increased respiratory rate, cyanotic mucosa and loss of consciousness. Endoscopic evaluation of the upper airways revealed no anatomical conformation changes or tissue dysfunction. The airways were free without secretion in the trachea. Radiographic evaluation of the head, heart and lung revealed only a slight increase in the cardiac silhouette. Ultrasound echocardiographic evaluations were performed using a convex probe with a frequency of $5.0 \mathrm{MHz}$ in the right parasternal window in the lateral position. The intercostal spaces were evaluated in positions three to five of the right hemithorax in transverse and longitudinal sections of both the left and right ventricles as well as the corresponding atrium. A loss of continuity in the wall of the interventricular septum was observed, with direct communication between the ventricles (Figure 1), thickening of the right ventricular wall and a hyperechoic appearance without clear definition of valve movement in the tricuspid valve region. There was also increased frequency. The crises have become more severe and more frequent, the animal began to show signs of ischemia, such as loss of motor coordination and limited mobility. The foal died at 15 days old. At necropsy, the liver was congested and had a nutmeg appearance, there was foam in the trachea, and the lungs were edematous. There was hydropericardium, and the heart was increased in size with a globoid shape.

The walls of the right atrium and ventricle were thickened (Figure 1A), and there was pulmonary artery stenosis (Figure 1B). There was also an oval shaped hole of $2.5 \mathrm{~cm}$ in diameter connecting the ventricles (Figure $1 \mathrm{~A}$ ), overriding of the aorta (Figure $1 \mathrm{C}$ ) and tricuspid valve aplasia (Figure 1D). The other organs had no macroscopic changes. Fragments of all of the organs in the abdominal and thoracic cavities and the central nervous system were fixed in $10 \%$ buffered formalin, routinely processed and stained with hematoxylin and eosin. Histologically, the liver had centrilobular to mediozonal necrosis, and there was pulmonary edema and congestion.

\section{DISCUSSION}

The diagnosis of pentalogy of Fallot was based on the clinical signs, the ultrasound results and the macroscopic lesions observed at necropsy. Tetralogy of Fallot is an embryonic defect of genetic or environmental origin [4] and is one of the most common congenital cardiac malformations observed in horses [5], however, in a study of congenital malformations in this species, only $3.5 \%$ had cardiac malformations out of the 608 foals examined. The prevalence of heart defects in horses compared with other domestic species is relatively low $(0.1 \%-0.5 \%)$ [6]. The Arabian breed seems to have a predisposition to congenital heart defects [6]. In the Crioulo breed, congenital defect reports are scarce. In a retrospective study of equine diseases in southern Brazil over a period of 35 years, malformations were

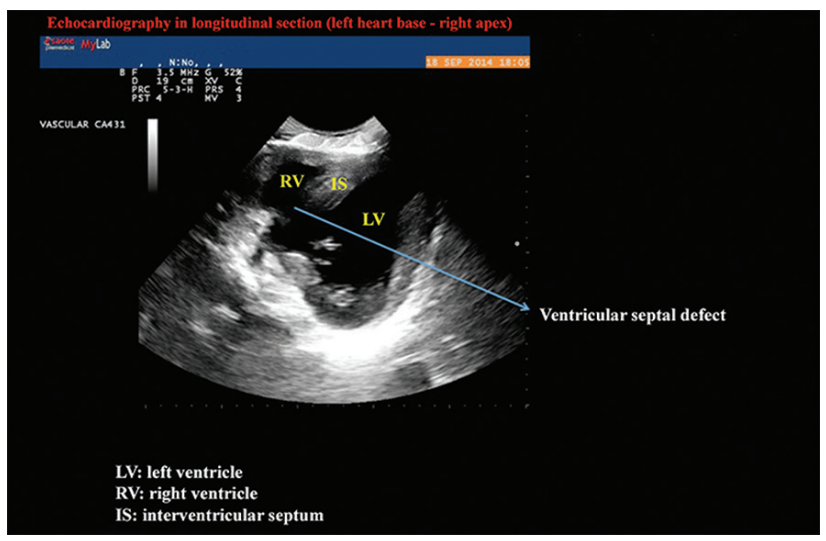

Figure 1. Pentalogy of Fallot in a Crioulo foal. Echocardiography in longitudinal section showing ventricular septal defect. 

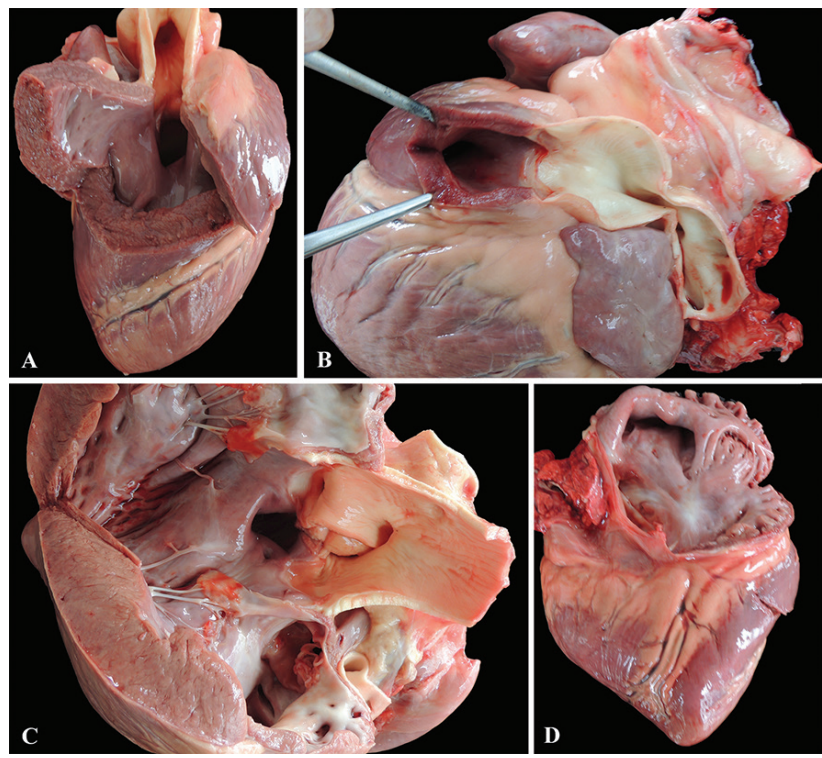

Figure 2. Pentalogy of Fallot in a Crioulo foal. A. Right ventricle view. There is a $2.5 \mathrm{~cm}$ subaortic ventricular septal defect and the right ventricular wall showed marked hypertrophy. B. Right atrium view. Pulmonary artery showing stenosis. C. Left ventricular view. An overriding aorta communicating with the right ventricle. D. Right atrium view. There is atresia of the right atrioventricular orifice (tricuspid atresia).

not observed in 708 horses of this breed, which is the predominant breed in the region [8].

In the present case, the foal was the son of a mare who had had three normal foals, all children of the same stallion. The mare and the other horses on the farm were vaccinated for herpes, influenza, strangles, leptospirosis and rabies. The clinical diagnosis of TOF was made by the changes observed by echocardiographic ultrasonography. However, during the necropsy, five cardiac defects were noted, characterizing POF. The suggestive diagnosis of POF, as well as TOF, may be accomplished by radiographic examination and electrocardiogram, in which a thickening of the right ventricular wall, pulmonary artery dilatation, pulmonary hypoperfusion and right heart axis deviation are observed. Echocardiography is another important method for the diagnosis of this malformation, showing a small size of the left intraventricular cavity, an interventricular septal defect and pulmonary artery stenosis [7]. In the case reported here, the foal showed clinical signs at her seventh day of life. However, not all horses with congenital cardiovascular lesions show clinical signs early in life [10]. The onset of clinical signs in cases of cardiac malformations can be variable and is probably due to differences in the development of collateral circulation and the severity of the degeneration of the pulmonary vasculature, leading to persistent hypoxia [11].

In Arabian horses, genetic hereditary factors may be involved in cardiac malformations [3]. In the present case, the fact that the mare had another three healthy foals with the same stallion reduces the possibility that this was a case of hereditary origin. On the farm, there was no history of any other animal born with malformations. It is likely that this case is of a sporadic nature with no chance of determining the cause.

The differential diagnoses in animals with lethargy, cyanosis, and exercise intolerance or syncope include complicated or multiple cardiac defects $[3,11]$. In southern Brazil, Rhodococcus equi infection causes pneumonia in foals from one to six months of age, and the clinical signs of respiratory distress and pulmonary stertor may be similar to those observed with cardiac malformations; however, this disease progresses with fever, and hematological evaluation shows a leukocytosis with neutrophilia that does not occur with malformations. In Rhodococcus equi infection, cyanosis and syncope are not observed, which are characteristic of cardiac malformations. There are no previous reports of TOF and POF in the Crioulo breed.

\section{MANUFACTURERS}

${ }^{1}$ UCBVet. Ribeirão Preto, SP, Brazil.

${ }^{2}$ Zoetis Brasil. São Paulo, SP. Brazil.

Declaration of interest. The authors report no conflicts of interest. The authors alone are responsible for the content and writing of the paper.

\section{REFERENCES}

1 Amorim S., Cuz C., Macedo F., Bastos P.T. \& Gonçalves F.R. 2005. Tetralogia de Fallot: Factores de Prognóstico após Cirurgia de Correção. Revista Portuguesa de Cardiologia. 24(6): 845-855.

2 Bailliar F. \& Anderson R.H. 2009. Tetralogy of Fallot. Orphanet Journal of Rare Diseases. 4(2): 1-10.

3 Bayly W.M., Reed S.M., Leathers C.W., Brown C.M., Traub J.L., Paradis M.R. \& Palmer G.H. 1982. Multiple congenital heart anomalies in five Arabian foals. Journal of the American Veterinary Medical Association. 181(7): 684-689.

4 Besser T.E. \& Knowlen G.G. 1992. Ventricular septal defects in bovine twins. American Journal of Veterinary Research. 200: 1355- 1356. 
5 Cargile J., Lombard C., Wilson J.H. \& Buergelt C.D. 1991. Tetralogy of Fallot and segmental uterine aplasia in a three-year-old morgan filly. Cornell Veterinarian. 81(4): 411-418.

6 Hall T.L., Magdesian K.G. \& Kittleson M.D. 2010. Congenital cardiac defects in neonatal foals: 18 cases (1992-2007). Journal of Veterinary Internal Medicine. 24: 206-212.

7 Larsson M.H.M.A., Pereira L., Jatene F.B., Freitas R.F., Barbusci L.O.D., Oliveira S.M. \& Abduch M.C.D. 2000. Clinical diagnosis and alternative surgical treatment of tetralogy of Fallot in a dog. A case report. Arquivo Brasileiro de Medicina Veterinária e Zootecnia. 52(5): 433-436.

8 Marcolongo-Pereira C., Estima-Silva P., Soares M.P., Sallis E.S.V., Grecco F.B., Fernandes C.G., Raffi M.B. \& Schild A.L. 2014. Doenças de equinos na região Sul do Rio Grande do Sul. Pesquisa Veterinária Brasileira. 34(3): 205-210.

9 Pazzi P., Lim C.K. \& Steyl J. 2014. Tetralogy of Fallot and atrial septal defect in a white Bengal Tiger cub (Panthera tigris tigris). Acta Veterinaria Scandinavica. 56: 12.

10 Rahal C., Collatos C., Solano M. \& Bildfell R. 1997. Pentology of Fallot, renal infarction and renal abscess in a mare. Journal of Equine Veterinary Science. 17(11): 604-607.

11 Vitums A. \& Bayly W.M. 1982. Pulmonary atresia with dextroposition of the aorta and ventricular septal defect in three Arabian foals. Veterinary Pathology. 19(2): 160-168. 